\title{
Model Rantai Pasok Pada Sistem Produksi Menggunakan Petri Net dan Aljabar Max Plus
}

\author{
Ahmad Afif $^{1}$, Dian Mustofani ${ }^{2}$ \\ ${ }^{1}$ Institut Ilmu Kesehatan Bhakti Wiyata Kediri, ahmad.afif@iik.ac.id \\ ${ }^{2}$ Institut Ilmu Kesehatan Bhakti Wiyata Kediri, dian.mustofani@iik.ac.id
}

\begin{abstract}
Supply chain production system is a process of coordination and integration of activities ranging from the procurement of goods and services, transforming raw materials into semi-finished goods and finished goods, to distribute to the consumers in an efficient manner. Supply chain analysis is used to regulate the supply of the production system so as not to overload so that it can reduce the costs of the entire production system which includes the costs of processing, transportation and distribution of raw materials, semi-finished goods and finished goods. Petrinet can describe the supply chain model as a dynamic production systems with discrete events with max plus algebra approach to help calculate the length of time in the distribution and production in the supply chain.
\end{abstract}

Keywords: supply chain, production system, petri net, max plus algebra

\begin{abstract}
Abstrak. Rantai pasok pada sistem produksi merupakan proses koordinasi dan integrasi kegiatan mulai dari pengadaan barang dan jasa, mengubah bahan baku menjadi barang setengah jadi dan barang jadi, hingga mendistribusikan kepada konsumen dengan cara efisien. Analisis rantai pasok dipakai untuk mengatur pasokan dari sistem produksi supaya tidak terjadi overload sehingga dapat mengurangi biaya dari keseluruhan sistem produksi yang meliputi biaya pengolahan, transportasi dan distribusi bahan baku, barang setengah jadi dan barang jadi. Petrinet dapat menggambarkan model rantai pasok sebagai sistem produksi yang dinamis dengan kejadian diskrit dengan pendekatan aljabar max plus untuk membantu menghitung lamanya waktu dalam pendistribusian dan produksi dalam rantai pasok.
\end{abstract}

Kata kunci : rantai pasok, sistem produksi, petri net, aljabar max plus

\section{Pendahuluan}

Persaingan produksi dalam pasar global semakin ketat, pengenalan produk kepada pelanggan semakin cepat dan tentu harapan terhadap produk dan jasa juga semakin tinggi. Hal ini memaksa semua perusahaan untuk lebih memfokuskan perhatian dalam proses persediaan produk atau jasa demi menunjang kelangsungan usahanya. Perkembangan sistem transportasi dan komunikasi membawa pengaruh besar terhadap perubahan rantai produksi dan manajemen distribusinya.

Dalam (Guritno \& Harsasi, n.d.) suatu rantai produksi, bahan baku diperoleh dan diproduksi dalam proses pengolahan, kemudian dikirim ke gudang 
penyimpanan, hingga diterima pengecer (retailer) atau pelanggan. Sehingga barang yang akan diproduksi harus sesuai dengan jumlah, waktu dan tujuan dari rencana awal produksi untuk mencapai biaya minimum. Untuk mengurangi biaya operasional dan meningkatkan kualitas pelayanan, perlu dilakukan strategi rantai persediaan yang efektif dan efisien. Rantai persediaan atau jaringan logistik, terdiri dari penyalur, manufaktur, gudang, distribusi dan retailer, seperti halnya bahan baku, barang setengah jadi dan barang jadi.

Analisis rantai pasok muncul sebagai solusi untuk mengefisiensi biaya seoptimal mungkin dari keseluruhan sistem produksi yang meliputi biaya transportasi dan distribusi ke sentral bahan baku, barang setengah jadi dalam proses pengolahan dan barang jadi. (Guritno \& Harsasi, n.d.) Menyebutkan penekanan biaya tidak semata - mata sebagai upaya memperkecil ongkos transportasi atau mengurangi persediaan yang ada, melainkan sebagai upaya pengembangan melalui perubahan sistem secara keseluruhan untuk menyediakan material sampai produk yang ditunjang dengan teknologi yang memadai dalam keseluruhan sistem rantai pasok yang ada.

Dalam tulisan ini akan dibangun model petrinet yang menggambarkan rantai pasok sebagai sistem produksi yang dinamis dengan kejadian diskrit dan menyajikan petrinet dengan pendekatan pemodelan aljabar max plus untuk membantu menghitung lamanya waktu dalam pendistribusian dan produksi dalam rantai pasok. Sistem produksi dalam penelitian ini terdiri dari dua produsen penyedia bahan baku dan satu produsen kemasan yang kemudian berproduksi menjadi satu secara bersama dalam memproduksi barang siap pakai hingga disalurkan kepada dua jenis konsumen yang berbeda, yaitu tradisional dan modern.

\section{Landasan Teori}

\subsection{Rantai Pasok}

Manajemen rantai pasok pertama kali dikenalkan oleh Weber dan Oliver pada tahun 1982. Manajemen rantai pasok merupakan proses koordinasi dan integrasi kegiatan yang dimulai dari pengadaan barang dan jasa, mengubah bahan baku menjadi barang dalam proses dan barang jadi, dan mengantarkan barang-barang tersebut kepada para pelanggannya dengan cara efisien. Koordinasi dan integrasi merupakan elemen penting untuk melakukan upaya sinkronisasi sehingga bila semuanya dilakukan dengan baik maka efisiensi biaya akan diperoleh dan dapat digunakan sebagai strategi bersaing terhadap kompetitor lain.

Elemen-elemen yang mempengaruhi rantai pasok diantaranya adalah supplier, pusat manufaktur, gudang, pusat distribusi, sistem transportasi, retail outlet, dan konsumen. Agar rantai pasok dapat berjalan dengan baik diperlukan koordinasi yang bagus antar elemen rantai pasok tersebut. Selain itu kondisi yang baik setiap elemen juga dapat mempengaruhi berjalannya rantai pasokan.

Salah satu cara untuk dapat mengkoordinasi antara elemen-elemen sistem rantai pasok adalah dengan membuat model dan menganalisis sistem kompleks dari rantai pasok. Hal ini merupakan hal yang penting agar dapat mengevaluasi kinerja dan membuat perbandingan jalanya rantai pasok. 


\subsection{Petri Net}

Petri net dikembangkan pertama kali oleh matematikawan asal Jerman yang bernama Carl Adam Petri pada tahun 1962. Petri net merupakan alat bantu memodelkan system event diskrite. System event diskrite adalah suatu sistem dimana ruang keadaan dijabarkan oleh himpunan diskrit $\{0,1,2, \ldots\}$ dan transisi keadaan hanya diamati pada titik diskrit dalam waktu. Jadi, perubahan keadaan pada system event diskrite diakibatkan oleh terjadinya event (Wattimena, Freya N., Pentury, 2012).

Petri net merupakan graf berarah yang memiliki dua node yang dinamakan sebagai Place dan Transisi. Place dilambangkan sebagai lingkaran (circles) dan Transisi dilambangkan sebagai persegi panjang (bars) (Wattimena, Freya N., Pentury, 2012). Setiap place dapat berisi satu atau lebih token, yang dilambangkan dengan bulatan kecil (dots). Antara place dan transisi dihubungkan oleh anak panah ( $a r c)$. Pada petri net graf diperbolehkan menggunakan beberapa arc untuk menghubungkan dua node atau lebih dengan memberikan bobot ke setiap arc yang menyatakan jumlah arc (Mustofani, Dian., Afif, 2018).

Petri net dengan waktu (timed petri net) dikarakterisasi oleh $\mathrm{P}, \mathrm{T}, \mathrm{A}, w, x_{0}$ dan $\mathcal{T}$ dimana $\mathrm{P}$ adalah himpunan place, $\mathrm{T}$ adalah himpunan transisi, $\mathrm{A}$ adalah himpunan arc, $w$ adalah bobot masing - masing arc, $x_{0}$ adalah keadaan awal token pada setiap place dan $\mathcal{T}$ adalah vektor yang elemen - elemennya menunjukkan waktu yang diperlukan token berada dalam place sebelum downstream transisi enabled.

Transisi pada petri net menyatakan event pada system event diskrete. Event dapat terjadi jika terpenuhi terlebih dahulu beberapa keadaan. Keadaan pada petri net dinyatakan dengan place. Place dapat berfungsi sebagai masukan atau keluaran suatu transisi. Place sebagai masukan menyatakan keadaan yang harus dipenuhi agar transisi dapat terjadi. Setelah transisi terjadi maka keadaan akan berubah. Place yang menyatakan keadaan tersebut adalah keluaran dari transisi.

\subsection{Ajabar Max-Plus}

Aljabar max-plus merupakan perluasan aljabar linier biasa, dimana operasi yang digunakan adalah maksimum dan tambah. Elemen dari aljabar max-plus adalah bilangan real dan $\varepsilon \stackrel{\text { def }}{=}-\infty$. Selanjutnya, himpunan $\mathbb{R} \cup\{\varepsilon\}$ ditulis $\mathbb{R}_{\varepsilon}$ dengan $\mathbb{R}$ adalah himpunan bilangan real dan $\varepsilon \stackrel{\text { def }}{=}-\infty$. Pada $\mathbb{R}_{\varepsilon}$ didefinisikan operasi berikut: $\forall x, y \in \mathbb{R}_{\varepsilon \text {, }}$

$$
x \oplus y \stackrel{\text { def }}{=} \max \{x, y\} \text { dan } x \otimes y \stackrel{\text { def }}{=} x+y
$$

dimana operasi $\oplus$ dibaca $o$-plus dan $\otimes$ dibaca $o$-times .

Diberikan $\left(\mathbb{R}_{\varepsilon}, \oplus, \otimes\right)$ merupakan semiring dengan elemen netral $\varepsilon$ dan elemen satuan $e=0$. Untuk mempermudah penulisan semiring $\left(\mathbb{R}_{\varepsilon}, \oplus, \otimes\right)$ ditulis sebagai $\mathbb{R}_{\max }$.

Pemilihan simbol $\oplus$ dan $\otimes$ dalam aljabar max-plus masing - masing merupakan analogi dari operasi + dan $\times$. Sehingga proses perkalian dua matriks pada aljabar max-plus dapat juga disamakan dengan aljabar linier biasa. Perkalian dua matriks pada aljabar linier biasa menggunakan operasi "kali" dan "tambah", sedangkan pada aljabar max-plus menggunakan operasi "tambah" dan "maksimum" sebagai ganti dari operasi "kali" dan "tambah" yang digunakan proses perkalian dua matriks pada aljabar biasa.

$$
[A \oplus B]_{i, j}=a_{i, j} \oplus b_{i, j}=\max \left\{a_{i, j}, b_{i, j}\right\}
$$


dan

untuk setiap $i, j$.

$$
[\mathrm{A} \otimes \mathrm{B}]_{i, j}=\bigoplus_{k=1}^{p} a_{i, k} \otimes b_{k, j}=\max _{k \in \underline{p}}\left\{a_{i, k}+b_{k, j}\right\}
$$

\section{Pembahasan}

Untuk membuat sebuah manajeman rantai pasok diperlukan adanya urutan pengelolaan barang dan jasa yang ada didalamnya. Dimana dalam urutan pengelolaan tersebut harus diketahui gambaran sesungguhnya dan lengkap yang memperlihatkan keseluruhan mata rantai yang ada, dimulai dari awal pengelolaan hingga akhir. Rantai pasok pada sistem produksi berikut terdiri dua produsen penyedia bahan baku dan satu produsen kemasan yang kemudian berproduksi menjadi satu secara bersama dalam memproduksi barang siap pakai hingga disalurkan kepada dua jenis konsumen yang berbeda, yaitu tradisional dan modern. Secara alur dapat dilihat pada gambar 2.

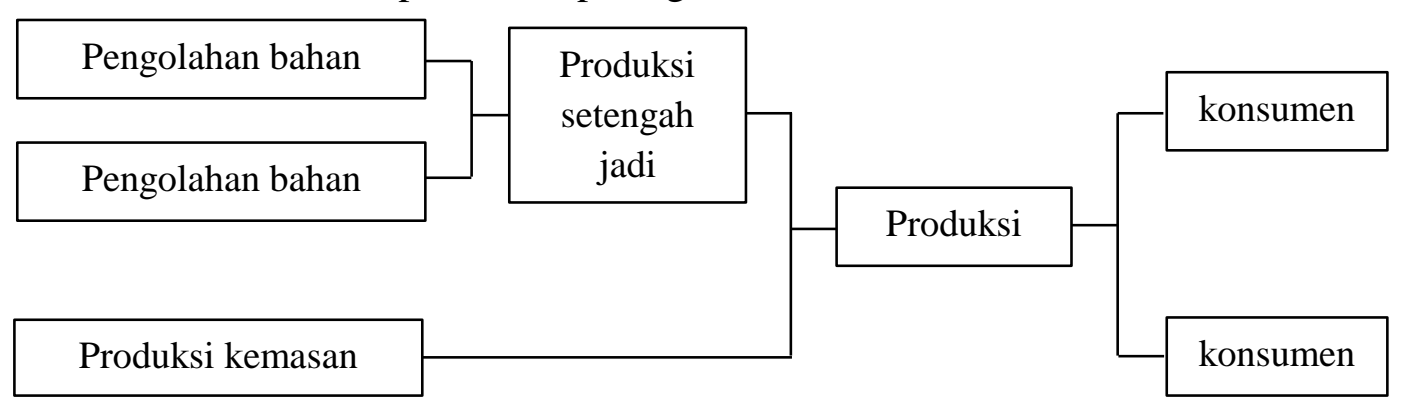

Gambar 2. Rantai pasok pada sistem produksi

Pada setiap proses pengolahan bahan baku dan produksi kemasan hingga produksi barang jadi terdapat sistem produksi sendiri yang meliputi penyediaan bahan baku, gudang, produksi dan pengiriman sehingga akan terjadi beberapa proses antrian. Proses antrian terjadi dikarenakan pada proses pengolahan dan produksi di asumsikan hanya memiliki seperangkat mesin produksi dan pada pengiriman hanya mampu mengangkut satu kali produksi. Sehingga proses pengolahan dan produksi berikutnya akan selalu menunggu produksi dan pengiriman selesai sampai pada tahap berikutnya. Sedangkan transportasi pada distribusi barang jadi ke konsumen dilakukan oleh 2 kendaraan sejenis yang saling bergantian untuk melakukan distribusi ke konsumen tradisional dan modern. Konsumen tradisional meliputi retail dari pertokoan kecil dan pasar, sedangkan konsumen modern meliputi swalayan dan kebutuhan ekspor.

Input bahan baku dan kemasan terdapat buffer dengan kapasitas yang cukup besar untuk menjamin bahwa buffer tidak akan pernah overflow. Suatu unit pemroses hanya bisa mulai bekerja untuk melanjutkan tahap berikutnya jika telah menyelesaikan proses sebelumnya. Diasumsikan juga bahwa setiap unit pemroses sesegera mungkin mulai bekerja bila semua komponen pendukung telah tersedia. Selanjutnya, rantai pasok pada sistem produksi disimulasikan dengan petri net yang dibuat dengan program PIPE sebagai berikut. 


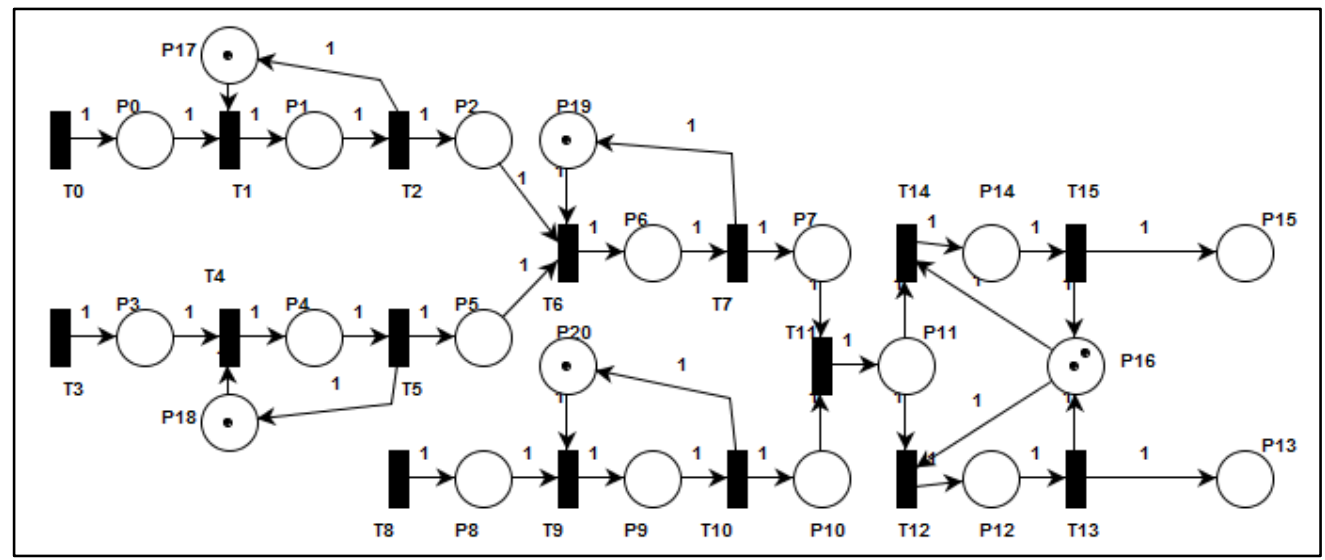

Gambar 3. Petri net pada rantai pasok pada sistem produksi

Rantai pasok pada sistem produksi yang telah disimulasikan dengan petri net akan dimodelkan menggunakan aljabar max-plus untuk mengetahui kinerja dari rantai pasok pada sistem produksi, yaitu mengetahui lama waktu dan waktu berakhirnya proses produksi. Berikut diberikan pendefinisian variabel pada model rantai pasok pada sistem produksi.

Tabel 1. Pendefinisian Variabel

\begin{tabular}{|c|c|c|c|}
\hline Var. & $\begin{array}{c}\text { Definisi Model Rantai Pasok } \\
\text { Sistem Produksi } \\
\end{array}$ & Var. & $\begin{array}{c}\begin{array}{c}\text { Definisi Model Rantai Pasok } \\
\text { Sistem Produksi }\end{array} \\
\end{array}$ \\
\hline$t_{0}(k)$ & $\begin{array}{l}\text { Waktu pemasok bahan baku I } \\
\text { saat ke- } k\end{array}$ & $v_{0, k}$ & $\begin{array}{l}\text { Lamanya memasok bahan baku I } \\
\text { saat ke- } k\end{array}$ \\
\hline$t_{1}(k)$ & $\begin{array}{l}\text { Waktu pengolahan bahan baku I } \\
\text { saat ke- } k\end{array}$ & $v_{1, k}$ & $\begin{array}{l}\text { Lamanya mengolah bahan baku I } \\
\text { saat ke- } k\end{array}$ \\
\hline$t_{2}(k)$ & $\begin{array}{l}\text { Waktu mulai distribusi hasil } \\
\text { pengolahan bahan baku I saat } \\
\text { ke-k }\end{array}$ & $v_{2, k}$ & $\begin{array}{l}\text { Lamanya mendistribusi hasil } \\
\text { pengolahan bahan baku I saat ke- } k\end{array}$ \\
\hline$t_{3}(k)$ & $\begin{array}{l}\text { Waktu pemasok bahan baku II } \\
\text { saat ke- } k\end{array}$ & $v_{3, k}$ & $\begin{array}{l}\text { Lamanya memasok bahan baku II } \\
\text { saat ke- } k\end{array}$ \\
\hline$t_{4}(k)$ & $\begin{array}{l}\text { Waktu pengolahan bahan baku } \\
\text { II saat ke- } k\end{array}$ & $v_{4, k}$ & $\begin{array}{l}\text { Lamanya mengolah bahan baku II } \\
\text { saat ke- } k\end{array}$ \\
\hline$t_{5}(k)$ & $\begin{array}{l}\text { Waktu mulai distribusi hasil } \\
\text { pengolahan bahan baku II saat } \\
\text { ke- } k\end{array}$ & $v_{5, k}$ & $\begin{array}{l}\text { Lamanya mendistribusi hasil } \\
\text { pengolahan bahan baku II saat ke- } k\end{array}$ \\
\hline$t_{6}(k)$ & $\begin{array}{l}\text { Waktu produksi barang setengah } \\
\text { jadi saat ke- } k\end{array}$ & $v_{6, k}$ & $\begin{array}{l}\text { Lamanya memproduksi } \\
\text { setengah jadi saat ke- } k\end{array}$ \\
\hline$t_{7}(k)$ & $\begin{array}{l}\text { Waktu mulai distribusi barang } \\
\text { setengah jadi saat ke- } k\end{array}$ & $v_{7, k}$ & $\begin{array}{l}\text { Lamanya mendistribusi barang } \\
\text { setengah jadi saat ke- } k\end{array}$ \\
\hline$t_{8}(k)$ & $\begin{array}{l}\text { Waktu pemasok bahan kemasan } \\
\text { saat ke- } k\end{array}$ & $v_{8, k}$ & $\begin{array}{l}\text { Lamanya memasok bahan kemasan } \\
\text { saat ke- } k\end{array}$ \\
\hline$t_{9}(k)$ & $\begin{array}{l}\text { Waktu produksi bahan kemasan } \\
\text { saat ke- } k\end{array}$ & $v_{9, k}$ & $\begin{array}{l}\text { Lamanya memproduksi bahan } \\
\text { kemasan saat ke- } k\end{array}$ \\
\hline$t_{10}(k)$ & $\begin{array}{l}\text { Waktu mulai distribusi produk } \\
\text { kemasan saat ke- } k\end{array}$ & $v_{10, k}$ & $\begin{array}{l}\text { Lamanya mendistribusi produk } \\
\text { kemasan saat ke- } k\end{array}$ \\
\hline$t_{11}(k)$ & $\begin{array}{l}\text { Waktu perakitan barang jadi saat } \\
\text { ke- } k\end{array}$ & $v_{11, k}$ & $\begin{array}{l}\text { Lamanya merakit barang jadi saat } \\
\text { ke- } k\end{array}$ \\
\hline
\end{tabular}


$t_{12}(k)$ Waktu mulai distribusi ke $v_{12, k}$ Lamanya mendistribusi ke konsumen modern saat ke- $k \quad 12, k \quad$ konsumen modern saat ke- $k$

$t_{13}(k)$ Waktu diterima di konsumen $v_{13, k}$ Lamanya berada di konsumen modern saat ke- $k \quad$ modern saat ke- $k$

$t_{14}(k)$ Waktu mulai distribusi ke $v_{14, k}$ Lamanya mendistribusi ke konsumen tradisional saat ke- $k$

$t_{15}(k)$ Waktu diterima di konsumen $v_{15, k}$ konsumen tradisional saat ke- $k$ tradisional saat ke- $k$ Lamanya berada di konsumen tradisional saat ke- $k$

Berdasarkan Tabel Pendefinisian Variabel dan model petri net maka dapat disusun model aljabar max-plus untuk rantai pasok pada sistem produksi dalam bentuk matriks sebagai berikut.

$$
x(k)=\left\{\begin{array}{lr}
A_{1} \otimes x(k-1) \oplus A_{2} \otimes x(k-2), & k \geq 3 \\
B \otimes y(k), & k=1,2
\end{array}\right.
$$

dengan $x, A_{1}, A_{2}, B$ dan $y$ sebagai berikut.

$A_{1}=\left[\begin{array}{lll}a_{1,1} & a_{1,2} & a_{1,3} \\ a_{2,1} & a_{2,2} & a_{2,3} \\ a_{3,1} & a_{3,2} & a_{3,3}\end{array}\right]$,

$a_{1,1}=\left[\begin{array}{ccc}a_{3,1} & v_{0, k} & a_{3,3} \\ v_{0, k}+v_{1, k} & v_{1, k} & \varepsilon \\ \varepsilon & \varepsilon & v_{3, k}\end{array}\right], a_{1,2}=\left[\begin{array}{ccc}\varepsilon & \varepsilon & \varepsilon \\ \varepsilon & \varepsilon & \varepsilon \\ \varepsilon & \varepsilon & \varepsilon\end{array}\right], a_{1,3}=\left[\begin{array}{ccc}\varepsilon & \varepsilon & \varepsilon \\ \varepsilon & \varepsilon & \varepsilon \\ \varepsilon & \varepsilon & \varepsilon\end{array}\right]$

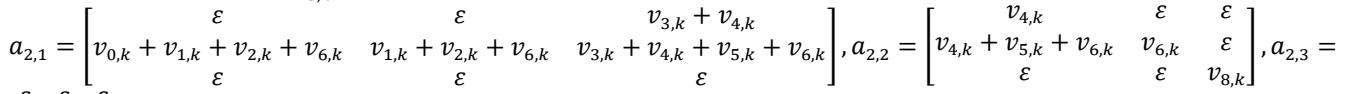

$\left[\begin{array}{lll}\varepsilon & \varepsilon & \varepsilon \\ \varepsilon & \varepsilon & \varepsilon \\ \varepsilon & \varepsilon & \varepsilon\end{array}\right]$

$\underset{a_{3,1}}{\stackrel{\varepsilon}{=}}$

$\left.\begin{array}{ccc}\varepsilon & \varepsilon & \varepsilon \\ v_{0, k}+v_{1, k}+v_{2, k}+v_{6, k}+v_{7, k}+v_{11, k}+v_{12, k} & v_{1, k}+v_{2, k}+v_{6, k}+v_{7, k}+v_{11, k}+v_{12, k} & v_{3, k}+v_{4, k}+v_{5, k}+v_{6, k}+v_{7, k}+v_{11, k}+v_{12, k}\end{array}\right]$,

$\left[\begin{array}{lll}v_{0, k}+v_{1, k}+v_{2, k}+v_{6, k}+v_{7, k}+v_{11, k}+v_{14, k} & v_{1, k}+v_{2, k}+v_{6, k}+v_{7, k}+v_{11, k}+v_{14, k} & v_{3, k}+v_{4, k}+v_{5, k}+v_{6, k}+v_{7, k}+v_{11, k}+v_{14, k}\end{array}\right]$

$a_{3,2}=\left[\begin{array}{ccc}\varepsilon & \varepsilon & v_{8, k}+v_{9, k} \\ v_{4, k}+v_{5, k}+v_{6, k}+v_{7, k}+v_{11, k}+v_{12, k} & v_{6, k}+v_{7, k}+v_{11, k}+v_{12, k} & v_{8, k}+v_{9, k}+v_{10, k}+v_{11, k}+v_{12, k}\end{array}\right]$

$\left[\begin{array}{ccc}v_{4, k}+v_{5, k}+v_{6, k}+v_{7, k}+v_{11, k}+v_{14, k} & v_{6, k}+v_{7, k}+v_{11, k}+v_{14, k} & v_{8, k}+v_{9, k}+v_{10, k}+v_{11, k}+v_{14, k}\end{array}\right]$

$a_{3,3}=\left[\begin{array}{ccc}v_{9, k} & \varepsilon & \varepsilon \\ v_{9, k}+v_{10, k}+v_{11, k}+v_{12, k} & v_{12, k} & v_{12, k} \\ v_{9, k}+v_{10, k}+v_{11, k}+v_{14, k} & v_{14, k} & v_{14, k}\end{array}\right]$

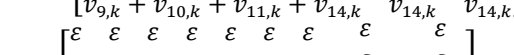

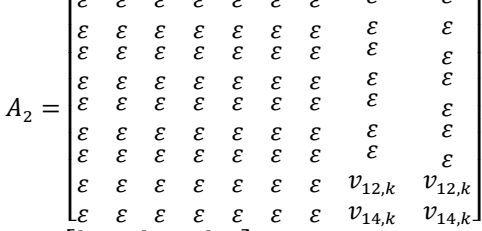

$B=\left[\begin{array}{lll}b_{1,1} & b_{1,2} & b_{1,3} \\ b_{2,1} & b_{2,2} & b_{2,3} \\ b_{3,1} & b_{3,2} & b_{3,3}\end{array}\right]$

$b_{1,1}=\left[\begin{array}{ccc}v_{0, k} & \varepsilon & \varepsilon \\ v_{0, k}+v_{1, k} & \varepsilon & \varepsilon \\ \varepsilon & \varepsilon & v_{3, k}\end{array}\right], b_{1,2}=\left[\begin{array}{lll}\varepsilon & \varepsilon & \varepsilon \\ \varepsilon & \varepsilon & \varepsilon \\ \varepsilon & \varepsilon & \varepsilon\end{array}\right], b_{1,3}=\left[\begin{array}{ccc}\varepsilon & \varepsilon & \varepsilon \\ \varepsilon & \varepsilon & \varepsilon \\ \varepsilon & \varepsilon & \varepsilon\end{array}\right]$,

$a_{2,1}=\left[\begin{array}{ccc}\varepsilon & \varepsilon & v_{3, k}+v_{4, k} \\ v_{0, k}+v_{1, k}+v_{2, k}+v_{6, k} & \varepsilon & v_{3, k}+v_{4, k}+v_{5, k}+v_{6, k} \\ \varepsilon & \varepsilon & \varepsilon\end{array}\right], a_{2,2}=\left[\begin{array}{ccc}v_{4, k} & \varepsilon & \varepsilon \\ v_{4, k}+v_{5, k}+v_{6, k} & v_{6, k} & \varepsilon \\ \varepsilon & \varepsilon & v_{8, k}\end{array}\right], a_{2,3}=\left[\begin{array}{ccc}\varepsilon & \varepsilon & \varepsilon \\ \varepsilon & \varepsilon & \varepsilon \\ \varepsilon & \varepsilon & \varepsilon\end{array}\right]$

$a_{3,1}=\left[\begin{array}{ccc}\varepsilon & \varepsilon & \varepsilon \\ v_{0, k}+v_{1, k}+v_{2, k}+v_{6, k}+v_{7, k}+v_{11, k}+v_{12, k} & \varepsilon & v_{3, k}+v_{4, k}+v_{5, k}+v_{6, k}+v_{7, k}+v_{11, k}+v_{12, k} \\ v_{0, k}+v_{1, k}+v_{2, k}+v_{6, k}+v_{7, k}+v_{11, k}+v_{14, k} & \varepsilon & v_{3, k}+v_{4, k}+v_{5, k}+v_{6, k}+v_{7, k}+v_{11, k}+v_{14, k}\end{array}\right]$,

$a_{3,2}=\left[\begin{array}{ccc}\varepsilon & \varepsilon & v_{8, k}+v_{9, k} \\ \varepsilon & v_{6, k}+v_{7, k}+v_{11, k}+v_{12, k} & v_{8, k}+v_{9, k}+v_{10, k}+v_{11, k}+v_{12, k} \\ \varepsilon & v_{6, k}+v_{7, k}+v_{11, k}+v_{14, k} & v_{8, k}+v_{9, k}+v_{10, k}+v_{11, k}+v_{14, k}\end{array}\right], a_{3,3}=\left[\begin{array}{ccc}\varepsilon & \varepsilon & \varepsilon \\ \varepsilon & \varepsilon & \varepsilon \\ \varepsilon & \varepsilon & \varepsilon\end{array}\right]$

$y=\left[\begin{array}{lllllllll}t_{0} & \varepsilon & t_{3} & \varepsilon & \varepsilon & t_{8} & \varepsilon & \varepsilon & \varepsilon\end{array}\right]^{T}$

Diberikan contoh permasalahan rantai pasok pada sistem produksi jika diberikan nilai lamanya waktu pada masing - masing proses produksi sebagai berikut. 
Tabel 2. Daftar Proses Sistem Produksi

\begin{tabular}{clc}
\hline Kode & \multicolumn{1}{c}{ Lama Proses Produksi } & Waktu (hari) \\
\hline$v_{0, k}$ & Lamanya memasok bahan baku I saat ke- $k$ & 2 \\
$v_{1, k}$ & Lamanya mengolah bahan baku I saat ke- $k$ & 1 \\
$v_{2, k}$ & Lamanya mendistribusi hasil pengolahan bahan baku I saat & 2 \\
& ke- $k$ & 3 \\
$v_{3, k}$ & Lamanya memasok bahan baku II saat ke- $k$ & 2 \\
$v_{4, k}$ & Lamanya mengolah bahan baku II saat ke- $k$ & 1 \\
$v_{5, k}$ & Lamanya mendistribusi hasil pengolahan bahan baku II saat & \\
& ke-k & 2 \\
$v_{6, k}$ & Lamanya memproduksi barang setengah jadi saat ke- $k$ & 3 \\
$v_{7, k}$ & Lamanya mendistribusi barang setengah jadi saat ke- $k$ & 4 \\
$v_{8, k}$ & Lamanya memasok bahan kemasan saat ke- $k$ & 2 \\
$v_{9, k}$ & Lamanya memproduksi bahan kemasan saat ke- $k$ & 2 \\
$v_{10, k}$ & Lamanya mendistribusi produk kemasan saat ke- $k$ & 2 \\
$v_{11, k}$ & Lamanya merakit barang jadi saat ke- $k$ & 3 \\
$v_{12, k}$ & Lamanya mendistribusi ke konsumen modern saat ke- $k$ & 2 \\
$v_{14, k}$ & Lamanya mendistribusi ke konsumen tradisional saat ke- $k$ & \\
\hline
\end{tabular}

Selanjutnya dari lamanya waktu yang diberikan untuk satu kali produksi jika saat ke-0 adalah tanggal 1 Februari, maka saat mulai produksi ke-1 bahan baku I akan tersedia pada 3 Februari, bahan baku II akan tersedia pada 4 Februari dan bahan kemasan akan tersedia pada 5 Februari. Hingga dibutuhkan waktu 16 hari dan 15 hari untuk menyelesaikan sampai pada masing - masing konsumen modern dan tradisional, yaitu tanggal 17 Februari dan 16 Februari. Berikut diberikan hasil saat ke $k=1,2,3$.

\begin{tabular}{clccc}
\hline Var. & \multicolumn{1}{c}{ Waktu Proses Produksi } & $k=1$ & $k=2$ & $k=3$ \\
\hline$t_{0}(k)$ & Waktu pemasok bahan baku I saat ke- $k$ & 2 & 4 & 6 \\
$t_{2}(k)$ & $\begin{array}{l}\text { Waktu mulai distribusi hasil pengolahan bahan } \\
\text { baku I saat ke- } k\end{array}$ & 3 & 5 & 7 \\
$t_{3}(k)$ & $\begin{array}{l}\text { Waktu pemasok bahan baku II saat ke- } k \\
t_{5}(k)\end{array}$ & 3 & 6 & 9 \\
& $\begin{array}{l}\text { Waktu mulai distribusi hasil pengolahan bahan } \\
t_{7}(k)\end{array}$ & 5 & 8 & 11 \\
$t_{8}(k)$ & Waktu mulai distribusi barang setengah jadi saat & & & \\
$t_{10}(k)$ & Waktu pemasok bahan kemasan saat ke- $k$ & 11 & 14 \\
$t_{13}(k)$ & Waktu diterima di swalayan dan ekspor saat ke- $k$ & 16 & 19 & 12 \\
$t_{15}(k)$ & Waktu diterima di pasar dan toko saat ke- $k$ & 15 & 18 & 21 \\
\hline
\end{tabular}

\section{Kesimpulan}

Berdasarkan model petri net dan aljabar max plus pada rantai pasok sistem produksi diatas dapat diketahui lamanya waktu proses pendistribusian dan produksi dari bahan baku dan kemasan hingga diterima konsumen modern dan 
tradisional. Hasil lamanya waktu tersebut dapat dipakai mengatur rantai pasok sistem produksi supaya tidak terjadi overload sehingga dapat mengurangi biaya dari keseluruhan sistem produksi yang meliputi biaya pengolahan, transportasi dan distribusi bahan baku, barang setengah jadi dan barang jadi.

\section{Daftar Pustaka}

B. Heidergott, G. J. Olsder, and J. van der Woude, 2006, Max Plus at Work, Princeton University Press, Princeton, New Jersey.

Baccelli, F., G. Cohen, G.J. Olsder, and J.-P. Quadrat. , 1992, Synchronization and Linearity, John Wiley and Sons, New York.

Guritno, A. D., \& Harsasi, M. (n.d.). Pengantar Manajemen Rantai Pasok ( Supply Chain Management ). 1-35.

Mustofani, Dian., Afif, A. (2018). Model Antrian Pelayanan Farmasi Menggunakan Petri Net Dan Aljabar Max-Plus. 3(2502-9878), 33-43. Retrieved from https://www.journal.unipdu.ac.id/index.php/jmpm/article/view/1055

Viswanadham, N. Raghvan Srinivasa, NR., 2000, Performance Analysis and Design of Supply Chains : a Petri net Approach, Journal of The Operational Research Society Vol.51, No.10, 1158-1169.

Wattimena, Freya N., Pentury, T. (2012). The Application of Petri Net in Electricity Bill Payment System of. 6(1), 23-30. 